\title{
AVALIAÇÃO FORMATIVA NA EAD: uma forma eficaz para (re) construção do conhecimento?
}

\author{
Eliane Juraski Camillo \\ Gislene Miot to Catolino Raymundo²
}

\section{RESUMO}

O presente artigo é resultado de uma pesquisa desenvolvida no Centro de Referência em Formação e EaD - Cerfead, diretoria vinculada à Pró-Reitoria de ensino - PROEN - que atua na implementação da política de formação do Instituto Federal Santa Catarina - IFSC. Por intermédio de abordagem qualitativa, tendo o questionário online como método de produção de dados, buscou-se averiguar, junto aos/às egressos/as do curso de Formação Continuada em EaD no IFSC turmas 2015/2 e 2016/1, suas visões e percepções acerca da av aliação formativa, perquirindo em que medida a mesma constituiu-se de uma forma eficaz de intervenção para (re)construção do conhecimento. Os principais referenciais teóricos com os quais dialogou-se, neste trabalho, foram: Vasconcellos (1998), Polak (2009), Perrenoud (1999), Otsuka (2002), Luckesi (2000), Hoffmann (2005) e Freire (2009). Os resultados apontam que a avaliação formativa auxilia, em grande medida, no processo de ensino e aprendizagem, fav orecendo a (re) construção do conhecimento.

Palavras-chave: Ensino. Educação a distância. Avaliação formativa.

\section{FORMATIVE EVALUATION IN EAD: an effective way for (re) construction of knowledge?}

\begin{abstract}
This article is the result of a research development out at the Reference Center for Training and EaD-Cerfead, a board of directors linked to the Pro-Rectorate of Teaching - PROEN - which is responsible for implementing the training policy of the Santa Catarina Federal Institute. Through a qualitative approach, having the online questionnaire as a method of data production, we sought to ascertain, with the graduates of the Continuing Education in Distance Education course at the IFSC classes $2015 / 2$ and $2016 / 1$, their visions and perceptions about formative ev aluation,

1 Doutora em Educação pela UFSM, docente do Instituto Federal de Santa Catarina - IFSC, lotada no Centro de Referência em Formação e EaD - Cerfead, em Florianópolis-SC. ORCID iD: https://orcid.org/0000-0002-6385-6629. E-mail: juraskicamillo@gmail.com

2 Doutora em Educação, docente do Instituto Federal de Santa Catarina - IFSC, lotada no Centro de Referência em Formação e EaD - Cerfead, em Florianópolis-SC. ORCID iD: https://orcid.org/0000-0001-8554-2359. E-mail: gismiotto@gmail.com
\end{abstract}

Revista Exitus, Santarém/PA, Vol. 9, Nº 3, p. 476 - 505, JUL/SET 2019. 
questioning to what extent and even constituted an effective form of intervention for (re) construction of knowledge. The main theoretical references that were discussed in this paper were Vasconcellos (1998), Polak (2009), Perrenoud (1999), Otsuka (2002), Luckesi (2000), Hoffmann (2005) e Freire (2009). The results indicate that the formative evaluation helps to a great extent, the teaching and learning process fav oring the (re) construction of knowledge.

Keywords: Teaching. Distance education. Formative ev aluation.

\section{EVALUACIÓN FORMATIVA EN EAD: una forma eficaz para (re) construcción del conocimento?}

\section{RESUMEN}

El presente artículo es el resultado de una investigación desarrollada en el Centro de Referencia en Formación y EaD-Cerfead, dirección vinculada a la Pro-Rectoría de enseñanza - PROEN - que actúa en la implementación de la política de formación del Instituto Federal Santa Catarina-IFSC. Por medio de un enfoque cualitativo, con el cuestionario en línea como método de producción de datos, se buscó av eriguar, junto a los/las egresados del curso de Formación Continuada en EaD en el IFSC clases 2015/2 y 2016/1, sus visiones y percepciones acerca de la evaluación formativa, preguntando en qué medida la misma se constituyó en una forma eficaz de intervención para (re) construcción del conocimiento. Los principales referenciales teóricos con los que se dialogó, en este trabajo, fueron: Vasconcellos (1998), Polak (2009), Perrenoud (1999), Otsuka (2002), Luckesi (2000), Hoffmann (2005) e Freire (2009). Los resultados apuntan que la ev aluación formativ a auxilia, en gran medida, en el proceso de enseñanza y aprendizaje, favoreciendo la (re) construcción del conocimiento.

Palabras clave: Enseñanza. Educación a distancia. Ev aluación formativa.

\section{PALAVRAS INICIAIS}

A premência da pesquisa da qual este artigo resultou, convém destacar, é oriunda de uma situação de ensino, vivenciada pela equipe docente no momento em que esta foi responsável pelo trabalho docente, quando da oferta do Curso de Formação Continuada em EaD no IFSC, a qual transcorreu no segundo semestre de 2015 e no primeiro semestre de 2016. Nesse ensejo, em comum acordo, a equipe docente decidiu por adotar como prática a avaliação formativa, dando retornos/feedbacks descritivos para cada atividade de aprendizagem enviada pelos/as alunos/as através da plataforma virtual Moodle (Modular Object-Oriented Dynamic Learning Environment), pela qual o curso se desenvolveu, com o 
intuito de melhor interferir e agir no processo de ensino e melhor orientar a aprendizagem dos discentes.

O fato de a pesquisa advir de uma situação de ensino é digno de nota, pois corrobora com o preceito da indissociabilidade entre ensino, pesquisa e extensão, que é o tripé no qual se assenta o trabalho pedagógico, nas universidades e também nos IFs, de acordo com o expresso em sua lei de criação, e sua oferta educativa, ampla, abarcando desde cursos de formação inicial e continuada em nível de ensino fundamental, indo até a oferta de cursos de pós-graduação stricto sensu, o que contempla, portanto, a oferta de cursos superiores, a exemplo das universidades.

Outra virtude desta pesquisa é que a mesma visa, também, acompanhar egressos/as, no que se refere à escuta junto aos sujeitos da aprendizagem, em relação ao processo de ensino e aprendizagem, vivenciado na oferta desse curso. Espartel (2009) e Pena (2000), ao discorrer sobre o tema Egresso, evidenciam que ao acompanhar os egressos em sua totalidade, as instituições estariam despertando para a sua própria realidade e, assim, estabelecendo estratégias para vencer seus obstáculos e conseguir, de fato, implementar uma educação comprometida com os sujeitos. Isso é possivel, observando-se a literatura teórica e empírica sobre o assunto, em conformidade com o que aconselha Flick (2009), constata-se que investigações em que a opinião dos/as alunos/as foi levada em conta, se mostraram muito valiosas. Isso porque, avaliar docentes, instituições, identificar motivos para escolha de determinados cursos, preferências por métodos de ensino, verificação de arrependimento com cursos escolhidos, bem como privilegiar a escuta atenta para outros pontos que os/as egressos/as tenham a manifestar, no caso específico desta pesquisa, a eficácia da avaliação formativa, pode constituir-se em uma ferramenta privilegiada de gestão, pois, para transformar realidades que assim careçam, antes é mister conhecê-las em profundidade.

E os/as egressos/as, naturalmente, são portadores/as de maior maturidade em relação ao processo já encerrado, conseguindo apresentar 
uma visão mais ampla sobre instituição e educação em sua totalidade, ao conseguir avaliar, de forma substancial, as contribuições que o curso trouxe para sua formação, não apenas profissional, mas integral, que é o objetivo maior da educação que se quer nos Institutos Federais, em consonância com a Lei $n^{\circ} 11.892 / 08$, que cria os mesmos como instituições especializadas na oferta de educação profissional e tecnológica.

O objetivo geral da presente pesquisa foi analisar as impressões que os/as alunos/as tiveram sobre a avaliação formativa, vivenciada no curso de formação continuada EaD no IFSC, por intermédio dos feedbacks que receberam dos docentes, referentes às produções das atividades de estudos realizadas. Como objetivos específicos, elegemos os seguintes: verificar a familiaridade dos/as alunos/as com a modalidade à distância; analisar o quanto a realização do curso contribuiu para o processo formativo dos/as alunos/as, especialmente, na (re)construção de conhecimentos sobre a oferta de cursos na modalidade à distância; verificar a concepção e familiaridade que os/as alunos/as apresentam com a avaliação formativa; constatar se para os/as alunos/as houve coerência entre a nota recebida pela produção das atividades e avaliação formativa emitida pelo/a docente; analisar a efetividade da avaliação formativa como forma de intervenção que possibilita a (re)construção de conhecimentos, especialmente nos cursos ofertados na modalidade a dist ância; verificar se a partir da experiência com a avaliação formativa o/a aluno/a utilizaria ou recomendaria a sua utilização como estratégia pedagógica; e analisar se a experiência vivenciada pelos/as alunos/as com a avaliação formativa, em cursos EaD possibilita/favorece 0 processo de (re)construção de conhecimentos.

Convém prevenir, no entanto, que não desejamos, por intermédio deste artigo, imprimir um caráter prescritivo em relação ao uso da avaliação formativa, já que, na prática, ela não acontece em situações idealizadas, mas em contextos reais, com estudantes reais e professores/as reais, que, por sua vez, necessitam de condições materiais adequadas de tempo e espaço para conseguirem realizar a prática da avaliação formativa, que é deveras 
complexa e requer bastantes horas de trabalho. O que se deseja, sim, é que esse estudo, embora não advindo, também, de um contexto ideal, em relação a essas condições materiais, especialmente, no que tange às condições adequadas de trabalho docente, possa inspirar reflexões e deslocamentos em relação à forma como a avaliação do ensinoaprendizagem acontece, especialmente, na EaD.

Na sequência, delinearemos e clarificaremos o percurso teóricometodológico percorrido pela pesquisa, bem como sobre o que estamos falando quando nos referimos à avaliação formativa e em que universo ela se circunscreve e que implicações isso traz para o estudo e para os resultados produzidos.

\section{Referencial teórico-metodológico - O universo dessa pesquisa na produção de conhecimento}

Ao envidarmos a busca de trabalhos que tratam sobre a avaliação formativa na EaD para dialogarmos, o fizemos no Banco de Dissertações e Teses da Capes, na página http://bancodeteses.capes.gov.br/bancoteses/\#!/. Buscando pelo descritor "avaliação formativa na educação a distância", foi disponibilizada 583537 dissertações e 195845 teses entre o período de 2002 a 2016 . Todavia, ao fazermos a análise dos títulos disponíveis e também a leitura dos resumos destes trabalhos, verificamos que apenas 14 tratavam de fato da temática da qual nos ocupamos nesse trabalho. São eles:

QUADRO 1 - Trabalhos encontrados na pesquisa realizada no Banco de dissertações e teses da Capes com descritor "avaliação formativa na educação a distância"

\begin{tabular}{|c|c|c|}
\hline Autor & Trabalho & $\begin{array}{l}\text { Ano de } \\
\text { Defesa }\end{array}$ \\
\hline $\begin{array}{c}\text { Moisés Zarzar } \\
\text { Correia de Melo }\end{array}$ & $\begin{array}{c}\text { Requisitos de Avaliação Formativa para Sistemas } \\
\text { Computacionais de Apoio ao Ensino e à } \\
\text { Aprendizagem }\end{array}$ & $01 / 02 / 2008$ \\
\hline $\begin{array}{c}\text { Ana Cristina } \\
\text { Muscas Caldeira }\end{array}$ & Avaliação Formativa na Educação Online & $01 / 02 / 2006$ \\
\hline & Gerenciador de Avaliações: uma Ferramenta de & $01 / 12 / 2003$ \\
\hline
\end{tabular}




\begin{tabular}{|c|c|c|}
\hline $\begin{array}{l}\text { Thaisa Barbosa } \\
\text { Ferreira }\end{array}$ & $\begin{array}{c}\text { Auxílio à Avaliação Formativa para o Ambiente de } \\
\text { Educação a Distância TelEduc }\end{array}$ & \\
\hline $\begin{array}{l}\text { Suzana Aparecida } \\
\text { Carvalheiro }\end{array}$ & $\begin{array}{c}\text { A experiência formativa diante da educação à } \\
\text { distância }\end{array}$ & $01 / 03 / 2002$ \\
\hline $\begin{array}{l}\text { Henrique de } \\
\text { Aguiar Sá Vila } \\
\text { Nova Júnior }\end{array}$ & $\begin{array}{c}\text { Visualização de Informação como Ferramenta de } \\
\text { Auxílio na Avaliação Formativa em Educação à } \\
\text { Distância }\end{array}$ & $01 / 04 / 2010$ \\
\hline $\begin{array}{l}\text { Cláudia Simone } \\
\text { Almeida de } \\
\text { Oliveira }\end{array}$ & $\begin{array}{c}\text { Avaliação da aprendizagem na educação online: } \\
\text { aproximações e distanciamento para uma avaliação } \\
\text { formativa-reguladora }\end{array}$ & $01 / 03 / 2010$ \\
\hline $\begin{array}{l}\text { Marcelle Patricia } \\
\text { Lopes Cunha }\end{array}$ & $\begin{array}{l}\text { A avaliação formativa no ambiente virtual de } \\
\text { aprendizagem moodle: um estudo no curso de } \\
\text { graduação em Pedagogia à distância da UFMA }\end{array}$ & $22 / 01 / 2014$ \\
\hline $\begin{array}{l}\text { Luís Fernando } \\
\text { Maximo }\end{array}$ & $\begin{array}{c}\text { A efetividade de feedbacks informatizados sobre a } \\
\text { autorregulação da aprendizagem em cursos à } \\
\text { distância: um estudo de caso na área da } \\
\text { Computação }\end{array}$ & $01 / 05 / 2009$ \\
\hline $\begin{array}{l}\text { Jaci Teixeira da } \\
\text { Silva }\end{array}$ & $\begin{array}{c}\text { Avaliação formativa com suporte de aluno tutor: } \\
\text { efeitos no rendimento classificado por nível cognitivo e } \\
\text { na satisfação dos alunos }\end{array}$ & $01 / 04 / 2002$ \\
\hline $\begin{array}{l}\text { Maria Elisabete } \\
\text { Bersch }\end{array}$ & $\begin{array}{l}\text { Avaliação da aprendizagem em educação à } \\
\text { distância online }\end{array}$ & $01 / 01 / 2009$ \\
\hline $\begin{array}{l}\text { Rosine Ribeiro } \\
\text { Corrêa }\end{array}$ & $\begin{array}{c}\text { Avaliação formativa. Mapa conceitual. } \\
\text { Autorregulação }\end{array}$ & $01 / 11 / 2009$ \\
\hline $\begin{array}{l}\text { João Batista } \\
\text { DAlbuquerque } \\
\text { Fonseca Filho }\end{array}$ & $\begin{array}{c}\text { Modelo de Apoio ao Tutor na Avaliação Formativa } \\
\text { Mediado por Agentes de Software }\end{array}$ & $01 / 02 / 2009$ \\
\hline Aírton Cavazzana & $\begin{array}{l}\text { O processo de avaliação formativa em ambiente } \\
\text { virtual de aprendizagem: um estudo exploratório com } \\
\text { professores e alunos de um Centro Universitário do } \\
\text { oeste do estado de São Paulo }\end{array}$ & $06 / 12 / 2010$ \\
\hline $\begin{array}{l}\text { Matheus Couto } \\
\text { de Oliveira }\end{array}$ & $\begin{array}{c}\text { Uma prática de avaliação formativa em ambientes } \\
\text { virtuais: processos de regulação e autorregulação da } \\
\text { aprendizagem em um curso de matemática à } \\
\text { distância }\end{array}$ & $19 / 12 / 2016$ \\
\hline
\end{tabular}

Fonte: Autoras.

Em relação à avaliação na educação à distância, Silva (2002, p. 27) ressalta que mesmo havendo uma significativa publicação sobre avaliação, ainda se "carece de pesquisa e de publicações a respeito da avaliação da aprendizagem adaptada à sua especificidade".

Em síntese, as pesquisas acima elencadas apontam: a) "indicativos que possibilitem a avaliação formativa em situações de aprendizagem à distância" (BERSCH, 2009 p.6); b) "que na modalidade de educação à distância, a avaliação formativa tem grande relevância, por favorecer acompanhamento do comportamento do aprendiz mesmo sem o feedback das interações face a face" (FERREIRA, 2003, p.06); c) "que avaliação 
formativa subsidia e orienta intervenções oportunas e adequadas às dificuldades de aprendizagem"; d) "a efetividade dos feedbacks informatizados sobre a autorregulação da aprendizagem dos alunos" (MAXIMO, 2009, p.07); e) "que a educação online pode favorecer a realização da avaliação formativa dos alunos, permitindo a individualização dos processos de aprendizagem, a interação social e autorreflexão" (CALDEIRA, 2006, p.06); f) "buscam compreender as dificuldades e desafios na concretização de uma avaliação Formativa-Reguladora, em um ambiente virtual de aprendizagem" (OLIVEIRA, 2016, p.08); g) "que o processo de avaliação formativa tem exigido que os educadores acompanhem a evolução dos alunos, elucidando dúvidas e aplicando avaliações periódicas, no intuito de avaliar o desempenho e identificar as dificuldades de aprendizagem" (FILHO, 2009, p.07); h) "que a avaliação formativa, em ambientes de educação à distância, pode ser realizada através de um contínuo acompanhamento da participação dos/das aprendizes ao longo do tempo" (JUNIOR, 2010, p.12); i) "a possibilidade de utilização das ferramentas do AVA Moodle, para a realização da avaliação formativa" (CUNHA, 2014, p.07); j) "que a prática de avaliação formativa, em Ambientes Virtuais de Aprendizagem, favorece os processos de regulação e autorregulação da aprendizagem" (OLIVEIRA, 2016, p.05); I) "a possibilidade de utilização das ferramentas do AVA Moodle, para a realização da avaliação formativa" (CUNHA, 2014, p.07); m) "que na modalidade de educação a distância, a avaliação formativa tem grande relevância, por favorecer o acompanhamento do comportamento do aprendiz" (FERREIRA, 2003, p. 11). Enfim, ao analisarmos os resumos dos trabalhos selecionados, percebemos que de alguma maneira, todos convergem para que a avaliação formativa pode ser concebida como uma prática de avaliação contínua que tem como objetivo melhorar as aprendizagens durante 0 desenvolvimento de um dado curso, contribuindo para o acompanhamento e orientação dos alunos durante todo o seu processo de formação" (PERRENOUD, 1999). 
Dessa forma, essa pesquisa pretende contribuir com as discussões que estão sendo realizadas em estudos sobre avaliação, especialmente a avaliação formativa na educação à distância. Apesar de existir uma produção bibliográfica relativamente extensa sobre esse tema, ainda há uma carência de estudos que a relacionem a um espaço privilegiado, no processo de ensinar e aprender na EaD. Dentre essas produções, citamos os estudos desenvolvidos por Esteban (1997), Hadji (2001), Hoffmann (1993; 2005), Luckesi (2000), Perrenoud (1999), Valente (2002), Otsuka (2002), Silva (2006), entre outros/as, que têm contribuído para que a avaliação da aprendizagem e a prática docente sejam repensadas, e novas alternativas apontadas, especialmente quanto à avaliação formativa na EaD.

\section{Sobre o que estamos falando}

De acordo com Vasconcellos (1998) e Luckesi (2000), quando falamos em avaliação no âmbito da educação, é possível compreendê-la sob duas formas: avaliação externa ou em larga escala e avaliação interna. Sobre as avaliações externas ou em larga escala, elas servem para produzir informações sobre o sistema educacional, sendo que o principal int uito delas é, sobremaneira, acompanhar se o que foi planejado está ou não se efetivando, sendo que, os dados podem servir como base para os/as gestores/as no (re)planejamento de ações em prol de melhorias necessárias.

Cumpre asseverar que as avaliações externas não são panaceia, tampouco "caça às bruxas". Em muitos ensejos, elas são impostas por atores externos à educação e à pedagogia, como o Banco Mundial, por exemplo, como condicionalidades para acordos e empréstimos. Como, em grande medida, essas avaliações são feitas por amostragem, elas nem sempre podem ser consideradas um retrato fiel da educação, em um determinado recorte espaciotemporal. Por essa razão, seus resultados nem sempre devem ser levados à risca e considerados pelas escolas e seus/suas gestores/as, sendo que, quando o contrário acontece, geralmente, isso pode estimular a competição e o ranqueamento entre estabelecimentos de ensino, o que não é salutar para a educação. 
A proximando-nos um pouco mais de nosso foco, a avaliação interna, segundo os vários/as autores/as que se ocupam em estudá-la e torná-la teoria e com os quais aqui dialogamos, a definem, grosso modo, como um meio para obter-se informações/subsídios, acerca da aprendizagem de alunos/as, considerando seus avanços e dificuldades em seu percurso formativo/caminhada escolar. Não devemos jamais confundir avaliação algo amplo, complexo e multifacetado - com instrumentos de avaliação. De acordo com Luckesi (2000), a avaliação, a qual deve orientar a aprendizagem, relaciona-se com aspectos sociais, éticos, psicológicos do processo de ensinar e aprender. Já os métodos/instrumentos de avaliação dizem respeito a aspectos técnicos e metodológicos do mesmo, como as provas, os trabalhos, os seminários, as arguições, etc.

Embora esses/as autores/as tenham produzido e incitado um profícuo diálogo sobre o assunto, contribuindo enormemente para a produção e o avanço do conhecimento sobre, é possível asseverar que ainda existe uma distância abissal entre essas teorias, e o que de fato, tem se vivenciado nos estabelecimentos de educação acerca da avaliação, fato esse que, da mesma forma, é examinado por esses/as autores/as. A avaliação, em muitos ensejos, ainda apresenta caráter classificatório e/ou é utilizada como uma forma de se garantir a disciplina na sala de aula. Abramowicz (2001, p.124) afirma que a "face controladora da avaliação como controle educacional ainda permite que percebamos mais uma dimensão: a ênfase no domínio cognitivo, expresso pelo controle dos conteúdos e pela insistência da memorização". Neste caso, não existe a possibilidade da (re)elaboração do conhecimento por parte do discente, pois os métodos levam à aceitação do conhecimento existente como sendo uma verdade absoluta. Segundo Vasconcellos (1998), o papel do professor no processo de ensinar e aprender transcende o mero ato de transmitir conteúdos para logo após verificar o que e em que medida os/as alunos/as assimilaram ou não os mesmos, traduzindo isso por intermédio de uma nota ou conceito. Dito em outras palavras, nessa perspectiva, a suposta aprendizagem corresponde à capacidade que o/a aluno/a tem ou não para memorizar informações e 
conseguir reproduzi-las. Assim, os/as alunos/as seriam classificados em aptos e não aptos, tendo o/a professor/a um presumível poder na vida do discente, ao permitir ou não que o referido possa prosseguir na sua caminhada escolar.

A avaliação do processo de aprendizagem constitui objeto de intensos debates dentro e fora da comunidade acadêmica, no entanto, ainda é concebida, reforçando o anteriormente dito, como um instrumento de controle utilizado pela burocracia escolar, que tem por finalidade selecionar os/as alunos/as que conseguiram atingir os objetivos educacionais pretendidos daqueles/as que não conseguiram (GONÇALVES, 2003). Diante desse contexto, podemos constatar a existência de uma prática avaliativa tradicional na sociedade contemporânea, que visa à exatidão das respostas e não possibilita aos/às alunos/as estabelecer relações entre os conteúdos científicos e sua realidade profissional e social.

No entanto, conscientes dessas questões, visualizamos ser urgente adotar outra concepção de avaliação, desenvolver um tipo de ação educativa e de avaliação que não procure moldar todos os/as alunos/as dentro do mesmo padrão social e cultural dominante, mas que valorize os saberes e as práticas de grupos sociais diferenciados, bem como as características individuais de cada aluno/a, promovendo/favorecendo, dessa maneira, a inclusão social e a formação da cidadania.

Nesse sentido, buscamos nesse estudo romper com a visão tradicional na prática avaliativa e concebê-la em uma perspectiva inclusiva, especialmente, na modalidade de ensino a distância, pois à devido ao uso pedagógico da web, há outras maneiras de viabilizar diferentes situações de aprendizagem e, portanto, de criar novos recursos didáticos e procedimentos avaliativos que viabilizem aos/às alunos/as uma aprendizagem mais interativa e colaborativa.

Dessa forma, a problemática proposta para discussão neste estudo refere-se à avaliação formativa utilizada no curso de Formação Continuada EaD no IFSC, especialmente em verificar se e em que medida os feedbacks que os/as alunos/as receberam dos/as docentes contribuíram para a 
(re)construção de conhecimentos. Na educação à distância, a interatividade no processo educativo deve ser planejada e direcionada para atender às necessidades e possibilidades cognitivas dos/as alunos/as. Assim, consideramos necessária, uma proposta avaliativa que extrapole a simples mensuração, traduzida por uma nota ou conceito. Nessa perspectiva, acreditamos que a avaliação formativa, além de promover a interação entre professores/as e alunos/as, incentiva a dialogicidade, e também possibilita a reflexão crítica sobre os conteúdos científicos, independente do distanciamento físico entre esses/as atores/as, pois, a presença nos ambientes virtuais de ensino e aprendizagem é caracterizada/incentivada pela qualidade do processo de interação que se estabelece.

Luckesi (2000, p.17) nos oferece uma valiosa contribuição no intuito de compreendermos o amplo sentido da avaliação na educação, que supera o acima dissertado:

A avaliação, para assumir o caráter transformador e não de mera constatação e classificação, antes de mais nada, deve estar comprometida com a promoção da aprendizagem e desenvolvimento por parte de todos os alunos. Esse é o sentido mais radical, é o que justifica sua existência no processo educativo.

E vai além:

A avaliação da aprendizagem, por ser avaliação, é amorosa, inclusiva, dinâmica e construtiva, diversa dos exames, que não são amorosos, são excludentes, não são construtivos, mas são classificatórios. A avaliação inclui, traz para dentro; os exames selecionam, excluem e marginalizam (LUCKESI, 2000, p. 7).

Esses dois excertos do autor são essenciais para compreender nosso intuito, quando do uso da avaliação formativa. Por essa, aliás, demarcamos aqui, que a avaliação formativa tem como principal objetivo acompanhar o processo de ensino e aprendizagem. Através dela, o/a professor/a enfatiza os resultados da aprendizagem e estabelece um comparativo entre os diferentes resultados obtidos pelo/a mesmo/a aluno/a. 
Nesse sentido, Sanmartí, enfatiza que

a avaliação mais importante para os resultados de aprendizagem é a realizada ao longo do processo de aprendizagem. A qualidade de um processo de ensino depende, em boa parte, de se conseguir ajudar os alunos a superarem os obstáculos em espaços de tempo pequenos no momento em que são detectados. Além disso, o fundamental para aprender é que o próprio aluno seja capaz de detectar suas dificuldades, compreendê-las e autorregulá-las (SANMARTí, 2009, p. 33).

Nesse sentido, a avaliação formativa é realizada no decorrer do ano letivo, com intuito de verificar se os/as alunos/as estão atingindo os objetivos de aprendizagem previstos. Esse tipo de avaliação é basicamente orientadora, pois encaminha tanto o estudo do/a aluno/a, quanto os procedimentos do/a professor/a. Ainda fornecem dados para uma tomada de decisão que pode ser no sentido de criar condições de melhoria do ensino, visando à aprendizagem, pois o processo não está finalizado.

Esse tipo de avaliação desempenha um papel orientador, ou seja, localiza deficiências no ensino e informa - professor/a e aluno/a - sobre o rendimento da aprendizagem, além de possibilitar ao/a educador/a, formas para que possa redirecionar o processo, propondo estudos de recuperação quando observado baixo aproveitamento escolar. Dessa forma, a prática formativa na avaliação tem como objetivo fazer com que todos/as possam (re)construir conhecimento e apropriarem-se dos saberes de maneira reflexiva. A avaliação formativa acompanha o processo de ensinoaprendizagem, verificando se os objetivos de aprendizagem estão sendo atingidos. Assim, constitui "uma importante fonte de informações para o atendimento às diferenças culturais, sociais, psicológicas dos educandos, o que se torna grande conquista na luta contra as desigualdades e o fracasso escolar" (PERRENOUD, 1999, p. 28).

E mais, 
formativa. Pelo fato de que obtermos conhecimento a partir da avaliação, podemos intervir inteligentemente de um modo justo, equânime, equitativo para aumentar 0 conhecimento de quem aprende e de quem ensina (MENDEZ, 2002 p.85).

Polak (2009, p. 154) também declara que a intencionalidade da avaliação formativa é possibilitar que o professor tenha acesso à "informação e comunicação para que se possa monitorar, apoiar e aperfeiçoar a aprendizagem do aluno, o que exige muito mais acompanhamento formativo do que o controle e a classificação dos resultados".

Nesse sentido, podemos elencar as principais características da avaliação formativa: tem como objetivo permitir ao/à professor/a compreender como o/a aluno/a elabora e (re)constrói seu próprio conhecimento; os registros não podem ser exclusivamente quantitativos, com notas ou mesmo conceitos, mas em forma de relatório e anotações; não tem como objetivo principal a definição de um conceito ou nota, mas o desenvolvimento do/a aluno/a, verificado durante o processo; prevê que os/as alunos/as têm ritmos e processos de aprendizagem diferentes, que permitem tornar a progressão da aprendizagem, a partir das necessidades e possibilidades de cada aluno/a; levanta a necessidade de investigação do conhecimento prévio do/a estudante para o (re)planejamento do trabalho como um todo.

No entanto, quando pensamos sobre os procedimentos avaliativos na educação à distância, a empreitada é ainda mais árdua! Barreiro-Pinto (2008, p. 32) declara que "esse imenso desafio na sala de aula presencial torna-se ainda maior na educação online, pela ausência das relações presenciais e pelas especificidades da educação na web". Nesse sentido, o uso pedagógico da web permite aos/às professores/as vivenciar diferentes maneiras de mediar situações de ensino e aprendizagem, além de possibilitar a criação de novos e diversificados procedimentos didáticos e instrumentos avaliativos que viabilizem a interatividade na construção do conhecimento. 
Certamente, você, caro/a leitor/a, deve estar se perguntando: Como avaliar na educação online, especialmente no ambiente virtual de aprendizagem? Que procedimentos avaliativos podem ser adotados? Quando e onde realizar? Quais critérios para correção devem ser adotados? Que tipo de avaliação pode ser utilizado? A busca para essas indagações é imprescindível para se evitar o que comumente ocorre no ensino presencial, que é denominado por Luckesi (2000) de "pedagogia do exame", isto é, a busca pelo produto expressado pela nota e/ou conceito é mais importante do que a qualidade do processo ensino e aprendizagem.

Freire (1999), explica que acreditar que conceitos ou notas possam por si só explicar a aprovação ou retenção de um/a aluno/a, sem que seja analisado todo o processo de ensino e aprendizagem, as condições que foram oferecidas para promover a aprendizagem deste/a aluno/a é, sobretudo, tornar o processo avaliativo redutivista, conduzindo a uma visão degradada do conhecimento e das relações sociais, contribuindo, assim, para alienação dos homens (e das mulheres), ideologizando-os (as).

Então, estamos diante de um imenso desafio: como avaliar os alunos na modalidade à distância e ainda romper com a cultura tradicional que permeia o processo avaliativo? Todavia, na educação à distância, precisamos repensar a nossa forma de ensinar e também de avaliar e isso requer

criar novos modelos e instrumentos capazes de trazer resultados satisfatórios e que sejam totalmente diferentes dos modelos tradicionais, uma vez que se trata de cursos a distância, logo se exige modelos diferentes dos presenciais. $O$ que se percebe, atualmente, em muitas instituições do país, é a reprodução de modelos presenciais em cursos à distância (RODRIGUES; BORGES, 2012, p. 27).

Barreiro-Pinto (2008, p.2) discute a "transposição para o ambiente online de concepções de avaliação voltadas para a aprendizagem presencial", mas destacando a necessidade de não se "perder de vista o contexto sócio técnico em que se dá a dinâmica comunicacional própria da internet [...]" e conclui (p.7) que é possível a transposição dos princípios 
da avaliação presencial para o ambiente online, "visto que tais princípios podem ser potencializados por meio da interatividade, permitida pela tecnologia. A interatividade, sob este aspecto, torna-se fundamental para a promoção da construção do conhecimento, de modo individual e/ou coletivo" (2008, p.7).

Nessa perspectiva, a avaliação formativa, nos cursos ofertados na modalidade à distância, pode ser realizada de forma contínua, utilizando-se de ferramentas síncronas e assíncronas, tais como mapeamento conceitual, criação de portfólios, comentários postados de forma individual ou de forma coletiva orientando o/a aluno/a, participações em grupos de discussão, em chats e mensagens enviadas de forma contínua, dentre outras formas mais.

A equipe docente responsável pela oferta do Curso de Formação Continuada em EaD no IFSC optou em adotar como prática a avaliação formativa, por intermédio de relatório descritivo que foi postado para cada aluno/a, utilizando-se no moodle da ferramenta "tarefa", com o intuito de informar aos/às alunos/as, o nível de aprendizagem dos conceitos trabalhados no curso, colaborando para que pudessem relacionar os conceitos/conteúdos aprendidos à realidade pessoal e profissional, especialmente relacionando com a oferta de um curso na modalidade EaD.

Em torno de 137 alunos tiveram feedbacks de suas atividades postadas no ambiente virtual de ensino e aprendizagem. Nossa intenção, reforçamos, excedendo a simples intenção de verificar o quanto nossos/as alunos/as aprenderam ou não, assumiu, pelas vias da avaliação formativa, um caráter transformador, pois, em conformidade com os dados produzidos e analisados, os sujeitos afirmaram que a mesma contribuiu para a promoção de uma aprendizagem mais efetiva, já que apontou (des)acertos e outras possibilidades que os/as alunos/as poderiam ter explorado em seu particular processo de ressignificação de conhecimentos estudados no curso. Na esteira disso, é possível afirmar que essa avaliação objetivou ao máximo ser amorosa, inclusiva e dinâmica, pois incluiu o/a aluno/a, considerando as suas necessidades e possibilidades de aprendizagem. Nesse sentido, além de se constituir em um ato amoroso, conforme ressalta Luckesi (2000), corrobora 
inclusive, para o cumprimento da missão institucional do IFSC, pois possibilita a promoção da inclusão.

\section{Sobre o percurso metodológico e o que é possível depreender a partir dos dados produzidos}

No tocante ao percurso metodológico, optamos por utilizar, com o objetivo de alcançar um melhor ajuste à pesquisa, mais especificamente, por entendermos que a mesma teria maior potencial de responder à pergunta de pesquisa, a abordagem qualitativa. O uso da referida abordagem na educação, segundo Flick (2009), vem crescendo muito ultimamente, dado que a abordagem qualitativa, por olhar e considerar as realidades de forma mais complexa e abrangente, tem maior possibilidade de encontrar as respostas (provisórias) de que essa área mestiça carece.

Ainda inspirados/as em Flick, optamos, como ferramenta de produção de dados, o questionário qualiquantitativo, contendo, portanto, questões abertas e fechadas. O uso do questionário, comunga com um dos preceitos do autor em voga, o qual discorre acerca de uma significativa mudança que vem se observando na pesquisa ultimamente, acerca do abrandamento da guerra de paradigmas de pesquisa, a qual vem sendo paulatinamente substituída pela triangulação. Em poucas palavras, a triangulação diz respeito à utilização combinada de métodos e ferramentas que se alinham ora com a pesquisa qualitativa, ora com a pesquisa quantitativa. Na verdade, cada perspectiva de pesquisa possui seu instrumental com o qual mais se alinha, sendo que um questionário fechado alinha-se mais com a pesquisa quantitativa. Todavia, mesmo considerando um maior alcance e profundidade da pesquisa qualitativa e de seus instrumentos e métodos, o fato é que cada método possui suas potencialidades e limitações, sendo que a escolha de um ou outro, deve se dar pela maior possibilidade de se obter resposta satisfatória à questão de pesquisa. Assim, quando se opta pela triangulação - ou seja - pela combinação de métodos qualitativos e quantitativos, ter-se-á uma maior 
possibilidade de se obter as respostas buscadas, pois, conforme dito, a potencialidade de um método tende a cobrir a limitação de outro.

No tocante à atribuição de significados aos dados produzidos, buscamos aporte na análise do discurso, sobretudo levando em conta as contribuições teóricas de Bardin (1977) e Orlandi (2007). Em termos operacionais, a interpretação dos discursos produzidos pelos/as estudantes que responderam o questionário centrou-se, primordialmente, na elaboração de grupos temáticos e/ou categorias, depreendidos/as da/na frequência pela qual, determinados elementos/temas/assuntos apareceram nas respostas dadas, como também prestamos atenção a elementos pouco citados, não os desconsiderando, haja vista que também são de valia no exercício interpretativo e muitas vezes, apontam para questões deveras importantes que comumente não são percebidas ou levadas em conta pelos/as pesquisadores/as.

O questionário para produção de dados e posterior análise foi disponibilizado aos/às alunos/as do curso de formação continuada EaD no IFSC, turmas 2015-2 e 2016.1, no seguinte link: http://goo.gl/forms/dSdX8UEOsP. O convite para participar da pesquisa foi feito no próprio ambiente Moodle, na sala de aula virtual do curso, através do envio de mensagem no campo "Fórum de Notícias", sendo que os/as discentes também receberam cópia da mensagem em seus endereços de e-mails pessoais, cadastrados na plataforma. O link do questionário igualmente foi disponibilizado no mesmo espaço.

Buscando atingir os objetivos elencados para a pesquisa, formulamos e disponibilizamos aos sujeitos discentes as seguintes questões: 1) "Você já tinha realizado algum curso na modalidade EaD? Indique quantos."; 2) "Descreva como foi o seu processo de aprendizagem neste curso."; 3) "No FIC EaD no IFSC, os/as professores/as ut ilizaram a avaliação formativa. O que você compreende por avaliação formativa?"; 4) "Em seu processo formativo, você já tinha recebido algum feedback por meio da avaliação formativa? Descreva o que achou desta experiência."; 5) "A avaliação formativa que você recebeu dos/as professores/as sobre a produção de 
suas atividades contribui para a sua aprendizagem?"; 6) Juntamente com a avaliação formativa recebida sobre a produção de suas atividades, você também recebeu uma nota. Você considera que essa nota está coerente com o relatório de avaliação formativa emitido pelo/a professor/a? Por quê?"; 7) A partir da vivência com a avaliação formativa, você utilizaria ou recomendaria a sua utilização como estratégia pedagógica? Justifique.".

Sobre os retornos do questionário, ambas as ofertas contavam com o total de 150 alunos/as, sendo que destes/as, 30 responderam as questões, o que equivale a um percentual de retornos de $20 \%$ do total dos alunos/as matriculados/as no/do curso. Sobre esse percentual, embora alguns/algumas possam considerá-lo baixo, convém salientar que, na pesquisa qualitativa, a questão da representatividade é vista de forma diferenciada. Não é correto considerar, nessa abordagem, que o percentual de discentes que respondeu o questionário seja portador/a da opinião da totalidade de matriculados/as no curso. Convém demarcar que o conhecimento produzido por intermédio desses sujeitos, restringe-se às impressões tidas por eles/as, não cabendo a nós (e a nenhum/a pesquisador/a que se aventura pelas searas da pesquisa qualitativa em educação!), estendê-las também aos/às demais discentes.

Ainda, com base em Flick (2009), ao tratar da pesquisa qualitativa online, ressaltando suas limitações e potencialidades - a exemplo de todos os demais métodos de pesquisa, conforme já aqui assinalado, possui como umas das potencialidades, o fato de ser extremamente barato, já que é possível se atingir um grande número de sujeitos ao mesmo tempo, com um custo estritamente reduzido, que foi o que aconteceu nesta pesquisa, na qual utilizou-se o próprio ambiente de aula, com a qual os/as discentes já estavam familiarizados, recordando que as mensagens enviadas ainda eram redirecionadas à conta de e-mail dos sujeitos, o que, no caso, garantia, diríamos, uma camada a mais de segurança de que os/as mesmos/as egressos/as que já haviam concluído o curso no ano de 2015 e que não mais acessavam a sala de aula virtual (ou quando o faziam por alguma eventual necessidade de rever algum assunto estudado, o faziam esporadicamente), 
mesmo assim tivessem recebido o questionário e tivessem, portanto, a possibilidade de retorná-lo.

Entretanto, no que concerne às limitações do método, as quais, cremos, justificam o percentual de retornos obtido, o mesmo Flick previne de que, embora o método abarque um grande número de sujeitos ao mesmo tempo, como não há a abordagem física, presencial, igualmente não há, dessa forma, garantias de que os sujeitos receberão/receberam o questionário, o que pode ser impedido, por exemplo, por problemas de ordem técnica, como falta de acesso ou interrupção temporária de acesso à internet ou a um computador pessoal ou ainda a um artefato de acesso à internet. Não há, portanto, como sabermos, se, no momento do envio do questionário, a totalidade dos sujeitos estava com acesso pleno à internet. Outra limitação é o convencimento para que o/a discente participasse da pesquisa, que nesse método é um tanto problemático, dado que, como não se teve contato presencial com os/as discentes, a única forma de convencê-los/as a participar, era através das mensagens enviadas convidando-os/as a fazerem. Conquanto que a mensagem foi enviada uma vez e foram enviadas, também, mais duas mensagens reforçando o convite, o objetivo da pesquisa e a sua importância, não há como saber de que forma os sujeitos compreenderam e significaram o convite. Sem contar, também, de que havia um significativo número de discentes que se matricularam no curso em suas duas ofertas e nunca o acessaram, bem como de desistentes no decorrer do mesmo, que certamente não mais acompanharam o desenvolvimento do curso, como supomos que acabavam por apagar as mensagens de e-mail recebidas relativas ao curso, já que, supostamente, como não estavam mais cursando, o assunto não interessava mais.

Tecidas as devidas justificativas, passaremos a analisar os dados efetivamente produzidos, não desconsiderando, porém, como um dado significativo, o acima dissertado. A respeito da questão 1, os dados produzidos apontam para o fato de que a grande maioria dos sujeitos (26) já havia feito, anteriormente, cursos na modalidade EaD, tendo, por isso, uma 
certa familiaridade com essa modalidade de educação, e apenas 4 declararam nunca ter feitos cursos nessa modalidade. Esse fato é explicado, pois segundo o Censo EAD.BR 2016, a quantidade de alunos/as beneficiados/as pela modalidade a distância é imensa. O Censo contabilizou 1.675.131 em cursos livres. Os números são expressivos e revelam - potencial da EAD para atender a demandas regulamentadas de educação e, especialmente, as demandas de formação continuada.

Sobre a questão 2, a qual pedia para descrever como foi o processo de aprendizagem no curso, 12 respostas enunciaram que foi ótimo/excelente ou muito bom. Dentre as justificativas, foi enfatizado pelos sujeitos a qualidade do material disponibilizado na sala de aula virtual (textos, vídeos), das interações estabelecidas, quer por videoconferência, quer por intermédio dos retornos rápidos aos questionamentos dos/as discentes, e das interlocuções que o mesmo possibilitou. Também foi pontuado como de grande valia para os sujeitos a intenção do curso - a saber - focalizar o planejamento e o desenvolvimento de cursos na modalidade EaD no IFSC, discutindo todas as etapas e os processos para tal. Cremos que o fato de os sujeitos apontarem isso deveu-se à condição em que a EaD se encontra na instituição, em momento de expansão e consolidação. O relato a seguir confirma nossa análise: "Muito interessante e com boas perspectivas de novas ações no IFSC". O PDI institucional prevê que os cursos podem ofertar até $20 \%$ de sua carga horária na modalidade EaD, o que é de grande valia no sentido de democratizar o acesso e a permanência de alunos/as trabalhadores/as, que é o principal público-alvo do IFSC. Segundo o censo da EAD.BR 2016 (p.33) "o perfil dos alunos que estudam à distância no Brasil é um indicador seguro do caráter inclusivo da modalidade. São 'trabalhadores que estudam', e não 'estudantes que trabalham'". Nesse sentido, urge aos/às servidores/as do IFSC, sejam docentes ou técnicos administrativos - doravante TAEs, terem o ensejo de formações análogas a que motivou essa pesquisa, dado que pretendem instrumentalizar os mesmos com um rol de conhecimentos/saberes 
necessários/suficientes para serem, de fato, atores/autores na oferta institucional da modalidade EaD.

Em relação à questão 2, ainda, 9 sujeitos consideraram seu processo de aprendizagem como satisfatório, com justificativas de que o curso cumpriu exatamente o que prometeu, sem maiores surpresas. Acreditamos que os sujeitos que se referiram a essa justificativa, também poderiam qualificar o curso como bom/muito bom/ótimo, pois, essa classificação dependerá da visão particular de cada sujeito. Para alguns/as, um curso que promete exatamente o que cumpriv, pode ser considerado de mérito. Para outros, que talvez estejam acostumados com expectativas altas, prometer apenas o que cumpriu é pouco, precisando ir além, na questão de surpreender positivamente. Esse dado nos chamou muito a atenção, sendo que os elementos trazidos pelos sujeitos não permitiram um direcionamento mais preciso, no sentido de compreender o fato de o curso ter cumprido, exatamente, com o que prometeu, seja uma espécie de limitação. Talvez esse dado pode, ser por nós, equipe docente, entendido pela necessidade de surpreender (positivamente) os/as discentes, o que também pode ser muito relativo, pois, não foi expresso em que, gostariam de ser surpreendidos/as, recordando, também, que isso é peculiar de cada sujeito. Uma pista que fica-nos sobre isso é, quiçá, a possibilidade de extrapolação dos conteúdos estudados. Outra justificativa apresentada para a sat isfação mediana foi o fato de que, a grande maioria dos alunos/as servidores/as que fizeram o curso são novos/as no IFSC e que chegam sem ter conhecimento da realidade institucional, sem contar que, ao adentrar na instituição, precisam inteirar-se de várias coisas simultaneamente, o que impede de depositarem grandes expectativas em uma coisa que realizam em particular, já que, precisam dar atenção a muitas das quais, ainda não têm um conhecimento prévio mais apurado.

E, finalmente, 5 sujeitos consideraram o seu processo de aprendizagem tumultuado (2) e insatisfatório (3). Para esses, a justificativa para assim o julgarem foi não terem muito tempo disponível para se dedicarem aos estudos e às atividades propostas, o que colima, de certa forma, com o 
aludido acima, acerca do grande número de servidores/as novos/as na instituição. $E$, para os/as que não são novos/as, tal quadro aponta para a atual situação de intensificação do trabalho, sobretudo dos/as docentes, sobre o qual há diversos trabalhos realizados, além de se configurar em um profícuo campo de pesquisa no tocante à educação profissional e tecnológica. Outra razão apresentada pelos discentes para o baixo grau de satisfação com o processo de aprendizagem nas duas ofertas do curso foi o excesso de conteúdos, adicionado do fato de os sujeitos os considerarem densos e os prazos considerados insuficientes, para a realização e o envio das atividades de aprendizagem e de avaliação. Esses dois pontos foram pauta de reunião de avaliação da equipe docente, sendo que, a opinião dos discentes serviu de subsídio para se repensar a quantidade de conteúdos, bem como as tarefas e os prazos, sendo que a equipe docente decidiu por acatar a sugestão/reclamação dos/as alunos/as, o que resultou na retirada de alguns conteúdos mais extensos, assim como na readequação das atividades propostas e uma revisão dos prazos, tornandoas mais dinâmicas, sem, contudo, perder na qualidade e na profundidade da abordagem. Destacamos, aqui, que levar em conta a opinião dos discentes egressos/as para preparar novas ofertas do curso, corrobora com a máxima freireana sobre avaliação, contida, inclusive, no PDI institucional, na seção que trata das concepções de avaliação, de que quando se fala em avaliação, não é correto o entendimento de que $A$ avalia $B$, mas que $A$ e B se avaliam mediatizados pelo processo. Assim, também nós, enquanto equipe docente, podemos lançar um olhar para nosso trabalho enquanto tal e ressignificá-lo, adequando-o na direção da aprendizagem dos/as discentes.

Diante das reflexões que os dados produzidos a partir da questão 2 suscitaram, é possível depreendemos que os discentes - em sua maioria tiveram uma aprendizagem significativa, considerando, inclusive, que os conhecimentos sobre EaD compõem um vasto cabedal e que, obviamente, não é possível esgotá-los em um único curso, mas, para muitos, esse ensejo serviu como uma pequena introdução ao tema. $E$, nos sentimos 
autorizados/as a deduzir que a avaliação formativa, empreendida, foi um dos elementos que contribuiu para essa aprendizagem significativa, cumprindo, assim, o objetivo maior da avaliação, discutido na seção anterior, a saber, em linhas gerais, recordando, orientar o processo de ensino e aprendizagem.

A questão 3, por seu turno, objetivou auscultar os sentidos atribuídos pelos/as discentes à avaliação formativa. Os dados produzidos nos autorizam a afirmar que a maior parte dos sujeitos possui uma visão da mesma que corrobora com o referencial adotado e explanado. Dois sujeitos a definiram, grosso modo, como um tipo de avaliação que dá feedbacks ao/à aluno/a sobre seus progressos no curso. Dez sujeitos a definiram como um tipo de avaliação, cujo enfoque reside no processo de ensino e aprendizagem, configurando-se, portanto, como uma prática que se preocupa muito mais com a aprendizagem dos discentes e seus redirecionamentos, do que numa nota ou conceito final, o que corresponderia a uma perspectiva tradicional da avaliação, conforme anteriormente exposto, excluindo-se, assim, a ênfase em uma acepção punitiva, classificatória e eliminatória da avaliação. Esses sujeit os entendem o papel do/a professor/a como mediador/a, no sentido de auxiliar os/as discentes a encontrarem o melhor caminho para envidarem a sua aprendizagem, contribuindo para uma formação mais holística, integral e reflexiva. A distinção do foco da avaliação formativa - do processo, em lugar do produto final, também foi percebida e citada por oito sujeitos. Apenas 3 sujeitos emitiram opiniões diversas sobre essa pergunta e que se afastam do que o referencial teórico adotado vaticina sobre. Ratificamos, logo, que não passou despercebido pelos/as discentes o uso da avaliação formativa no curso e que os/as mesmos/as possuem, de acordo com o referencial teórico adotado, visões clarificadoras sobre a mesma. Esse dado pode ser associado aos retornos da questão posterior, de número 4, a qual perguntava se os alunos haviam feito cursos em que teria se usado a avaliação formativa, sendo que, dos 30 sujeitos, 21 declararam que já 
haviam experienciado em algum momento de seu percurso formativo esse tipo de avaliação.

A questão de número 5 visou averiguar, junto aos sujeitos, as impressões que tiveram ao vivenciar a avaliação formativa. Dos 30 sujeitos, 27 consideraram a experiência: muito positiva (9); positiva (13) e interessante/razoável (5). Os argumentos apresentados, de certa forma, repetem o acima exposto, de que tal forma de avaliação, focada no processo, é interessante porque auxilia muito na aprendizagem por intermédio da reflexão, presente quando se é necessário repensar/reajustar os caminhos possíveis para determinadas aprendizagens. Vejamos a resposta de um/a aluno/a: "a partir do retorno que os professores davam eu podia rever os conteúdos que eu tinha maiores dificuldades". Outro/a aluno/a ainda afirma que "acredito que a possibilidade de receber o feedback constante, acerca do meu processo de aprendizagem é um grande estímulo e abriu um espaço mais amplo para a reflexão".

Chamou-nos a atenção um argumento exibido, de que o/a aluno/a sentiu-se muito mais valorizado/a, já que, o fato de o/a docente se preocupar com suas respostas em específico e devolver a ele/a um panorama de seus (des)acertos e outras possibilidades, mas foi deveras enriquecedor para sua formação e demonstrou, antes de qualquer coisa, o cuidado, o carinho e a atenção do/a docente para com seu modo peculiar de (re)construir conhecimentos, o que, mais uma vez, aponta, ao nosso ver, para o fato de a avaliação formativa constituir-se em uma ferramenta eficaz nessa direção. Tanto isso é factível que, para a questão posterior, de número 5, que interrogou se a avaliação formativa recebida havia ou não contribuído para uma aprendizagem mais efetiva, 27 dos 30 sujeitos declararam que sim e apenas 3 afirmaram que não. Otsuka e Rocha (2002) enfatizam que a avaliação formativa é baseada no "acompanhamento e orientação do aprendiz durante o desenv olvimento de tarefas significativas e relevantes ao mesmo, planejadas para levarem 0 aprendiz a um engajamento ativo na construção dos seus conhecimentos". 
Prosseguindo em nossa análise, a questão de número 6 objetivou perquirir se a equipe docente estava utilizando com propriedade e coerência a avaliação formativa, ao questionar se os/as discentes consideraram que as notas recebidas estavam coerentes com o relatório de avaliação formativa emitido pelo/a professor/a. Vinte e cinco sujeitos reconheceram haver coerência entre a nota e o relatório emitidos. Vejamos os relatos dos alunos: "Porque achei que nota foi justa pelo que fizemos, pois nossas tarefas exigiram estudo, tempo e compreensão das atividades", no entanto, ouro aluno afirma "demonstra o grau de percepção que eu tive da matéria dada, o que também estava em sintonia com o que o/a professor/a avaliou".

Por outro lado, apenas cinco sujeitos afirmaram que julgavam existir incoerência entre a nota e o relatório, sendo que, para esses/as, em vista do relatório, a nota deveria ter sido maior, alegando, desse modo, certo excesso de rigor na nota. Vejamos os relatos: "considero que minha nota na primeira atividade, de elaboração de PPC de curso EaD foi muito baixa" e ainda "Não é exatamente incoerência, mas inadequação do nível de exigência aplicado na atribuição da nota".

Esse dado, similarmente, foi foco de reflexão da equipe docente para ofertas posteriores, sendo que, combinou-se que quando um membro da equipe estivesse em dúvida entre essa relação entre a nota e o parecer, consultaria outro/a colega da equipe, para uma segunda ou terceira opinião. Sem contar de que, ter critérios de correção bem definidos, ajuda a refrear esse viés, sendo que, essa dúvida é de ocorrência mais comum, quando se trata de questões/tarefas cuja abordagem é mais qualitativa/subjetiva, ocasião em que, em muitos ensejos, fica mais difícil de mensurar por intermédio de uma nota, esta obrigatória, segundo o Regulamento Didático Pedagógico - RDP do IFSC.

E, por fim, a questão de número 7 buscou saber junto aos sujeitos se, a partir desta vivência de avaliação formativa, a recomendariam ou não e por quê. Mais uma vez, nossas expectativas positivas/afirmativas em relação à prática foram confirmadas: vinte e oito sujeitos revelaram e justificaram 
enfaticamente que utilizariam (os/as docentes) e/ou recomendariam a prática da avaliação formativa, pela significância do recurso, por deixar o/a aluno/a confortável em o que o/a espera em seu processo de formação e, em suma, por resgatar o verdadeiro papel da avaliação, em similaridade ao referencial teórico abordado, direcionado os discentes para a (re)construção de conhecimentos, não apenas classificando-o/a como apto/a ou não apto/a.

\section{Palavras finais}

Ao chegarmos ao término deste exercício reflexivo de escrita, fruto de nossa pesquisa, com base no diálogo envidado com os/as vários/as autores/as, cujo conhecimento nos serviu de base, bem como com os dados produzidos junto aos nossos sujeitos, ousamos sustentar que nosso objetivo geral fora alcançado e, ao analisar as impressões dos/as alunos/as sobre a experiência da avaliação formativa utilizada no curso, obtivemos as respostas para os desdobramentos que corresponderam aos nossos objetivos específicos.

Assim, constatamos que a maior parte dos/as discentes já possuía familiaridade com a modalidade à distância. Também concluímos que, em grande medida, o curso foi de valia para o processo formativo dos discentes, especificamente na (re)construção de conhecimentos acerca da oferta de cursos na modalidade EaD. Verificamos, ainda, que os/as discentes compartilham da concepção de avaliação formativa, utilizada como referencial teórico, sendo que apresentaram certa intimidade com os seus atravessamentos, os quais transpareceram, quando da exposição de suas concepções.

Constatou-se, também, que houve coerência, por parte da equipe docente, entre a nota e o relatório de avaliação formativa emitidos, o que revelou que os/as docentes usaram com propriedade o instrumento, o que não os/as libera, no entanto, de manter-se sempre vigilantes quanto ao uso, sendo que se tomou as devidas providências para tal, acima descritas. 
Em suma, os/as discentes, em sua maioria absoluta, descreveram a experiência da avaliação formativa como de plena efetividade no processo de (re)construção de conhecimentos, ao declarar o quão positiva consideraram a experiência para suas formações, reforçada pelo fato de que ou usariam a mesma ou a recomendariam. Tais dados trazem elementos suficientes para responder afirmativamente a pergunta que motivou essa pesquisa. Sim, a avaliação formativa na educação a distância pode ser considerada uma forma eficaz de intervenção para a (re)construção de conhecimentos. Almejamos que novas pesquisas sejam feitas e que venham a dialogar com nosso humilde achado, reforçando (ou refutando) nosso conhecimento produzido a partir das visões de nossos sujeitos e de nossas (re)interpretações sobre essa parte do real, de suma importância, quando o assunto na berlinda é Educação que se quer inclusiva.

\section{REFERÊNCIAS}

ABRAMOWICZ, A.; MELLO, R. R. de (Org.). Educação: pesquisas e práticas. Campinas: Papirus, 2001.

BARDIN, L. Análise de conteúdo. Lisboa: Edições 70, 1977.

BARREIRO-PINTO, I. A . Avaliar a aprendizagem na educação online: a transposição de procedimentos presenciais e a dinâmica específica da Web. In: Reunião Anual da Anped, 31, 2008, Caxambu-MG. Constituição Brasileira, Direitos Humanos e Educação. Disponível em http://31 reuniao.anped.org.br/1 trabalho/GT16-4700--Int.pdf. Acesso em: 23/10/2015.

BERSCH, M. E. Avaliação da aprendizagem em educação a distância online. Porto Alegre, 2009, 177f. Dissertação de Mestrado. PUC/RS. Faculdade de Educação, Pontifícia Universidade Católica do Rio Grande do Sul.

CALDEIRA, A. C. M. Avaliação Formativa na Educação On -line. São Paulo, 2006. 2005f. Dissertação. Pontifícia Universidade Católica de São Paulo Mestrado em Educação.

CARVALHEIRO, S. A. A experiência formativa diante da educação à distância. Mestrado em Educação. Universidade Federal de São Carlos UFSCAR, 2002. 
CA VAZZANA, A. O processo de avaliação formativa em ambiente virtual de aprendizagem: um estudo exploratório com professores e alunos de um Centro Universitário do oeste do estado de São Paulo. Presidente Prudente: [s.n], 2010.

CORRÊA, R. R. C. Avaliação formativa. Mapa conceitual. Autorregulação. 2009, 122f. Londrina. Dissertação (Mestrado) Universidade Est adual de Londrina.

CUNHA, M. P. L. A avaliação formativa no ambiente virtual de aprendizagem moodle: um estudo no curso de graduação em Pedagogia a distância da UFMA. São Luis, 2014. 126p. Programa de Pós-Graduação em Cultura e Sociedade da Universidade Federal do Maranhão.

ESPARTEL, L. B.O uso da opinião dos egressos como ferramenta de avaliação de cursos: o caso de uma instituição de ensino superior cat arinense. Revista Alcance-Eletrônica, v. 16, n 01 . ISSN 1983-716X, UNIVALI p. 102 -1 14, jan/abr. 2009. Disponível em: alcance@univali.br. A cesso em: 30 de setembro de 2017.

ESTEBAN, M.T. (org.). Avaliação: uma prática em busca de novos sentidos. Rio de Janeiro: DP\&A, 1997. (Coleção O sentido da escola).

FERREIRA, T.B. Gerenciador de Avaliações: uma Ferramenta de Auxílio à A valiação Formativa para o Ambiente de Educação a Distância TelEduc. Campinas-SP, 2003, 129f. Dissertação de Mestrado - Universidade Estadual de Campinas.

FILHO, J. B. D. F. Modelo de Apoio ao Tutor na Avaliação Formativa Mediado por Agentes de Software. Recife, 2009, 206. Dissertação (Mestrado) Universidade Federal de Pernanbuco.

FLICK, U. Introdução à pesquisa qualitativa. 3. ed Porto Alegre: Artmed, 2009.

FREIRE, P. Pedagogia da Autonomia: Saberes necessários à prática educativa. 12.ed. São Paulo: Paz e Terra, 1999.

GONÇALVES, M.I. R. Avaliação no contexto educacional online. In: SILVA, Marco. Avaliação da aprendizagem em educação online. São Paulo: Loyola, 2006.

HADJI, C. Avaliação desmistificada. Tradução Patrícia Chit toni Ramos. Porto Alegre: Artmed, 2001.

HOFFMANN, J. Avaliar para promover: as setas do caminho. 7.ed. Porto Alegre: Mediação, 2005. 
JUNIOR, H. de A.Sá V. N. Visualização de Informação como Ferramenta de Auxilio na Avaliação Formativa em Educação a Distância. Recife, 2010.97F. Dissertação (Mestrado) Universidade Federal de Pernambuco - Ciência da Computação.

LUCKESI, C. C. Avaliação da aprendizagem escolar. 10. ed. São Paulo: Cortez, 2000.

\section{MAXIMO, L. F. A efetividade de feedbacks informatizados sobre a} autorregulação da aprendizagem em cursos a distância: um estudo de caso na área da Computação. 2009, 150 f. Tese (doutorado).Universidade Federal do Rio Grande do Sul. Curso de Pós-Graduação em Informática na Educação.

MELO, M. Z. C. de. Requisitos de Avaliação Formativa para Sistemas Computacionais de Apoio ao Ensino e à Aprendizagem. 2008, $132 \mathrm{f}$. Dissertação (Mestrado) Universidade Federal de Pernambuco - Ciência da Computação.

MENDEZ, J. M. A. Avaliar para conhecer, examinar para excluir. Porto Alegre: Artmed Editora, 2002.

OLIVEIRA, C. S. A. de. Avaliação da aprendizagem na educação online: aproximações e distanciamento para uma avaliação formativa-reguladora. Recife, 2010. 203 f. Dissertação (Mestrado) Universidade Federal de Pernambuco.

OLIVEIRA, M.C. de. Uma prática de avaliação formativa em ambientes virtuais: processos de regulação e autorregulação da aprendizagem em um curso de matemática a distância. Campo Grande - Mato Grosso do Sul. 2016, 144p. Dissertação de Mestrado apresentada ao Curso de Mestrado em Educação Matemática da Universidade Federal de Mato Grosso do Sul.

ORLANDI, E. P. Análise do discurso: princípios \& procedimentos. Campinas: Pontes, 2007.

OTSUKA, J. L. Análise do processo de avaliação contínua em um curso totalmente a distância. In: Virtual Educa 2002, Valença, Espanha, 2002.

PENA, M.D. C. Acompanhamento de egressos: análise conceitual e sua aplicação no âmbito educacional brasileiro. Disponível em: http://www.joinville.ifsc.edu.br/ alexsandra/Artigo\%20Monica\%20DIniz.pdf Acesso em: 30 de setembro de 2017.

PERRENOUD, P. Avaliação: da excelência à regulação das aprendizagens entre duas lógicas. Porto Alegre: Artes Médicas, 1999. 
POLAK, Y. N. de S. Avaliação do aprendiz em EAD. In: LITTO, F. M.; FORMIGA, M. M. M. Educação a distância: o estado da arte. São Paulo: Pearson do Brasil, 2009.

RODRIGUES, N. V. M.; BORGES, F. T. A valiação da Aprendizagem em Educação a Distância Através de Fórum. Aracaju: Sergipe; Revista Ideias \&.Inovação, V. 01, n 02, maio de 2012, p. 25-34.

SANMARTÍ, N. Avaliar para aprender. Porto Alegre: Artmed, 2009.

SILVA, J. T. da. Avaliação Formativa com Suporte de Aluno Tutor: Efeitos no Rendimento Classificado por Nível Cognitivo e na Satisfação dos Alunos. 2002. Dissertação de mestrado (Mestrado em Mestrado Em Educação) Universidade Católica de Brasília.

SILVA, M. Avaliação da Aprendizagem em Educação Online. São Paulo: Edições Loyola, 2006.

VASCONCELLOS, C. dos S. Avaliação da aprendizagem: práticas de mudança para uma práxis transformadora. 4. ed. São Paulo: Libertad, 1998.

Recebido em: 26 de junho de 2018. Aprovado em: 13 de dezembro de 2018. 